\author{
Jan Florian Heuer \\ Paolo Pelosi \\ Peter Hermann \\ Christina Perske \\ Thomas A. Crozier \\ Wolfgang Brück \\ Michael Quintel
}

\section{Acute effects of intracranial hypertension and ARDS on pulmonary and neuronal damage: a randomized experimental study in pigs}

Received: 20 July 2010

Accepted: 18 February 2011

Published online: 5 May 2011

(c) The Author(s) 2011. This article is published with open access at Springerlink.com

This article is discussed in the editorial available at: doi:

10.1007/s00134-011-2233-1.

Electronic supplementary material The online version of this article (doi:10.1007/s00134-011-2232-2) contains supplementary material, which is available to authorized users.

J. F. Heuer $(\bowtie)$ - P. Hermann •

T. A. Crozier · M. Quintel

Department of Anaesthesiology,

Emergency and Intensive Care Medicine,

University of Göttingen Medical Center,

Göttingen, Germany

e-mail: jheuer@med.uni-goettingen.de

Tel.: +49-551-3922995

Fax: +49-551-398676

P. Hermann

e-mail: phermann@med.uni-goettingen.de

T. A. Crozier

e-mail: tcrozier@med.uni-goettingen.de

M. Quintel

e-mail: mquintel@med.uni-goettingen.de

\section{P. Pelos}

Dipartimento di Scienze Chirurgiche e

Diagnostiche Integrate, Universita' degli

Studi di Genova, Genoa, Italy

e-mail: ppelosi@hotmail.com

\section{Perske}

Department of Pathology,

University of Göttingen Medical Center, Göttingen, Germany

e-mail: tinaperske@med.uni-goettingen.de

W. Brück

Department of Neuropathology,

University of Göttingen Medical Center,

Göttingen, Germany

e-mail:wbrueck@med.uni-goettingen.de

Abstract Purpose: To determine reciprocal and synergistic effects of acute intracranial hypertension and ARDS on neuronal and pulmonary damage and to define possible mechanisms. Methods: Twenty-eight mechanically ventilated pigs were randomized to four groups of seven each: control; acute intracranial hypertension (AICH); acute respiratory distress syndrome (ARDS); acute respiratory distress syndrome in combination with acute intracranial hypertension (ARDS + AICH). $\mathrm{AICH}$ was induced with an intracranial balloon catheter and the inflation volume was adjusted to keep intracranial pressure (ICP) at
$30-40 \mathrm{cmH}_{2} \mathrm{O}$. ARDS was induced by oleic acid infusion. Respiratory function, hemodynamics, extravascular lung water index (ELWI), lung and brain computed tomography (CT) scans, as well as inflammatory mediators, $\mathrm{S} 100 \mathrm{~B}$, and neuronal serum enolase (NSE) were measured over a 4-h period. Lung and brain tissue were collected and examined at the end of the experiment. Results: In both healthy and injured lungs, AICH caused increases in NSE and TNFalpha plasma concentrations, extravascular lung water, and lung density in CT, the extent of poorly aerated (dystelectatic) and atelectatic lung regions, and an increase in the brain tissue water content. ARDS and $\mathrm{AICH}$ in combination induced damage in the hippocampus and decreased density in brain CT. Conclusions: AICH induces lung injury and also exacerbates preexisting damage. Increased extravascular lung water is an early marker. ARDS has a detrimental effect on the brain and acts synergistically with intracranial hypertension to cause histological hippocampal damage.

Keywords ABI - ARDS - ELWI · CT scan - Organ dysfunction 


\section{Introduction}

Acute intracranial hypertension (AICH), often caused by traumatic brain injury [1], and acute respiratory distress syndrome (ARDS) are life-threatening conditions. Up to $40 \%$ of patients with isolated AICH develop ARDS, which not only worsens neurological outcome but also increases mortality $[2,3]$.

Intracranial hypertension (AICH) and ARDS were thought to be independent pathological entities, but recent results have shown that they both interact and not only can worsen but actually trigger each other. AICH-associated pulmonary dysfunction was attributed only to the pulmonary venoconstriction and increased capillary permeability caused by increased sympathetic activity [4], but the latter was recently shown to also induce a systemic inflammatory response with pulmonary infiltration of activated polymorphonuclear neutrophils and endothelial dysfunction [5-7]. Conversely, ARDS itself induces a systemic inflammatory response with elevated cytokines [8] and neutrophil counts as well as dysfunction of other organs, including the brain [9]. Increased permeability of tight endothelial junctions in the lung and the brain can facilitate cross talk between the two organs [10, 11]. This is underlined by a study showing an initially normal lung function after massive brain injury, but diminished pulmonary tolerance after subsequent ex vivo mechanical ventilation and reperfusion of the lung [12].

Brain-lung cross talk went undetected because appropriate indicators of organ dysfunction were lacking. Brain damage with permeability changes of the bloodbrain barrier induces detectable circulating levels of neuron-specific enolase (NSE) and S100 protein [13-16]. These markers are located, inter alia, in cells of the central nervous system (CNS) [17-19], appear soon after injury, and correlate with severity, neurological outcome, and survival $[20,21]$. The hippocampus is the area most vulnerable to traumatic brain injury or hypoxia $[15,22$, 23]. Pulmonary changes are detected morphologically in the CT scan and functionally as an increase of extravascular lung water.

This study tested the hypotheses that (a) AICH induces lung injury and also further worsens pre-existing ARDS, (b) ARDS induces hippocampal damage in the absence of AICH, and (c) ARDS and AICH together cause more severe hippocampal damage.

\section{Materials and methods}

Animal preparation

All procedures were approved by our institutional animal study review board. Animal handling was in accordance with National Institutes of Health (NIH) guidelines.
Twenty-eight female domestic pigs (mean weight $61 \mathrm{~kg}$; range 52-65 kg) were used for the study. They were premedicated intramuscularly with $40 \mathrm{mg}$ azaperonium (Stresnil ${ }^{\circledR}$; Janssen, Austria). An ear vein was cannulated, anesthesia was induced with $3-5 \mathrm{mg} / \mathrm{kg}$ thiopentone and $4 \mathrm{mg} / \mathrm{kg}$ ketamine $\left(\mathrm{Ketaminol}^{\circledR}\right.$; Vetpharma, Zurich, Switzerland), and maintained with ketamine $\left(10 \mathrm{mg} \mathrm{kg}^{-1} \mathrm{~h}^{-1}\right)$ and midazolam $\left(1 \mathrm{mg} \mathrm{kg}^{-1}\right.$ $\mathrm{h}^{-1}$ ) infusions. A cuffed endotracheal tube (Portex 6.5, Portex, Germany) was inserted and the lungs were mechanically ventilated (Servo 300, Siemens, Germany) in volume-controlled mode with a positive end-expiratory pressure (PEEP) $5 \mathrm{cmH}_{2} \mathrm{O}$, inspiratory/expiratory ratio (I/E) 1:2, 100\% oxygen and tidal volume (VT) $8-10 \mathrm{ml} / \mathrm{kg}$. VT and respiratory rate were adjusted to maintain $\mathrm{PaCO}_{2}$ below $60 \mathrm{mmHg}$. End-tidal $\mathrm{CO}_{2}$ was monitored with a capnograph (Datex Capnomac Ultima ${ }^{\circledR}$, Finland). Ringer acetate was infused at rate of $3-4 \mathrm{ml} \mathrm{kg}^{-1} \mathrm{~h}^{-1}$. Peripheral oxygen saturation, electrocardiography (ECG), and non-invasive blood pressure were monitored continuously.

A Licox ${ }^{\circledR}$ triple lumen transcranial bolt was inserted through a burr hole in the right frontal region. A Licox ${ }^{\circledR}$ microcatheter oxygen electrode $\left(\mathrm{PtiO}_{2}\right)$, and probes for intracranial pressure (ICP) (Integra Neuroscience, Integra $\mathrm{GmbH}, 40880$ Ratingen, Germany) were inserted through the bolt into the white matter. The tips of these microprobes were placed approximately $25 \mathrm{~mm}$ below the dura (see ESM for details).

A 22-F Fogarty catheter was inserted through a separate burr hole $25 \mathrm{~mm}$ lateral to the right frontal region [24] in the animals of the AICH groups. A thermistortipped fiberoptic catheter (Pulsiocath, 4F FT PV 2024; Pulsion Medical System, Munich, Germany) was placed in a femoral artery. A pulmonary catheter (Volef, Pulsion Medical System, Munich, Germany) was inserted through a 5-F sheath introducer in the right internal jugular vein, and the position of the catheter tip confirmed by the pressure tracing. The catheters were connected to pressure transducers and to an integrated bedside monitor (PiCCO, Volef; Pulsion Medical Systems).

\section{Experimental protocol}

After instrumentation, the animals were placed in a prone position for the rest of the study and were transferred to the CT scanner without interrupting ventilation. After positioning in the $\mathrm{CT}$ scanner, baseline values were recorded.

An aleatory method was used to randomly allot the animals to one of four groups: control; AICH; ARDS; ARDS + AICH (Test procedure: ESM Fig. 1). Randomization was continued until all groups contained seven animals. 


\section{Acute intracranial hypertension}

AICH was induced by inflating the Fogarty catheter until the ICP was greater than $30 \mathrm{cmH}_{2} \mathrm{O}$. The inflation volume was adjusted during the study period to maintain ICP at $30-40 \mathrm{cmH}_{2} \mathrm{O}$. This was necessary in animals that developed hypercapnia.

\section{$A R D S$}

Lung injury was induced by injecting oleic acid $\left(0.1 \mathrm{ml} \mathrm{kg}^{-1}\right.$ in $20 \mathrm{ml}$ of warm saline) into the right atrium over a period of $15 \mathrm{~min}$ [25]. The injury was considered stable if after 60 min $\mathrm{PaO}_{2}$ was constantly lower than $200 \mathrm{mmHg}$ at an $\mathrm{FiO}_{2}$ of 1.0 .

\section{$A R D S+A I C H$}

Lung injury was established first and the Fogarty catheter was then inflated to induce intracranial hypertension.

\section{Control}

Control animals were instrumented in the same manner as the animals in the other groups, but had no intracranial Fogarty catheter.

\section{Measurements}

Measurements were performed at baseline $\left(T_{0}\right)$ and 60 , 120, and 240 min after inducing lesions or after baseline measurements in the control group $\left(T_{60}, T_{120}\right.$, and $T_{240}$, respectively; see ESM for details).

\section{Hemodynamics and gas exchange}

Cardiac output (CO), stroke volume, systemic and pulmonary pressures, extravascular lung water index (ELWI), and intrathoracic blood volume index (ITBI) were measured in triplicate by the same investigator with $20 \mathrm{ml}$ ice-cold $0.9 \%$ saline solution.

Arterial and mixed venous samples were collected and immediately analyzed for blood gases (ABL 510, Radiometer, Copenhagen, Denmark).

\section{CT of lung and brain}

The lungs were scanned from apex to base during an endexpiratory hold at a PEEP of $5 \mathrm{cmH}_{2} \mathrm{O}$ (GE Light Speed VCT, GE Medical Systems, thickness $5 \mathrm{~mm}$, interval
$0.5 \mathrm{~mm}, 100 \mathrm{~mA}, 100 \mathrm{kV})$. The method used for quantitative image analysis to assess lung density (Hounsfield units, $\mathrm{HU}$ ), gas and tissue volume, gas-tissue ratio ( $\mathrm{ml}$ gas/g lung tissue $[26,27]$ ), and extent of lung tissue aeration (normal, poor, and none) has been described previously [28] (see ESM for details). Analysis of individual lung regions was performed by dividing the lungs into ten equidistant horizontal sections along the sagittal axis.

Pulmonary parenchyma with a CT density ranging from $-1,000$ to $-900 \mathrm{HU}$ was classified as overinflated, a range of -900 to $-500 \mathrm{HU}$ as normal, -500 to $-100 \mathrm{HU}$ as poorly aerated (dystelectatic), and -100 to $+300 \mathrm{HU}$ as non-aerated (atelectatic).

Three consecutive horizontal sections starting three slices below the occlusion catheter were analyzed. The brain CT density window was set from -10 to $+100 \mathrm{HU}$. Decreased density (lower HU) represented a greater tissue water content, i.e., edema, whereas increased density represented an increase in blood content [29, 30].

\section{Intracranial pressure and brain tissue oxygenation}

Intracranial pressure, brain temperature, and regional oxygen tensions in blood and tissue were recorded continuously. ICP was kept at $30-40 \mathrm{cmH}_{2} \mathrm{O}$ by adjusting the inflation of the Fogarty catheter balloon.

\section{Data acquisition}

Data recording and analysis was performed using the Modular Intensive Care Data Acquisition System (MIDAS) developed by P. Herrmann and P. Nguyen (Institut für Biomedizinische Technik, Hochschule Mannheim, Germany; see ESM for details).

\section{Heart rate variability}

Heart rate variability (HRV) was calculated from normal R$\mathrm{R}$ intervals at baseline, $T_{60}$, and $T_{240}$. The ECG signal was screened manually and segments containing ectopic beats or arrhythmia were excluded. HRV calculations were performed with the software MATLAB (Version 7.8. The Mathworks, USA). Means and standard deviations of the normal R-R intervals (SDNN) and the confidence intervals were calculated with the MATLAB function "normfit" (normal parameter estimates). SDNN reflects the sympathetic and parasympathetic influence on HR variability [31].

\section{Laboratory data}

NSE and S100 concentrations were measured in heparinized arterial blood (lower levels of detection, NSE 
$1 \mu \mathrm{g} 1^{-1}$; S100 $0.02 \mu \mathrm{g} \mathrm{1^{-1 }}$ ). EDTA-blood samples for IL-6, IL-1 $\beta$, and TNF-alpha were measured with a pigspecific ELISA (Quantikine ${ }^{\circledR}$ P, R\&D Systems, USA). The minimum detectable concentrations are $5 \mathrm{pg} \mathrm{ml}^{-1}$ for TNF and $10 \mathrm{pg} \mathrm{ml}^{-1}$ for IL-6 and IL-1 $\beta$. Values below the detection level were counted as zero.

\section{Histology}

Tissue samples were analyzed independently by two experienced pathologists/neuropathologists blinded to the treatment group. If the assessments differed, the samples were re-examined and a final assessment was made.

\section{Lung}

Three tissue samples from each lobe (15 samples per animal) were fixed in paraformaldehyde, embedded in paraffin, cut into $5-\mu \mathrm{m}$ sections, and stained with hematoxylin-eosin.

The sections were scanned at $\times 20$, examined in detail at $\times 400$ magnification (Olympus BX41), and assessed with a semiquantitative score to grade the extent (area) and the severity (grade) of tissue damage, dystelectasis, pulmonary edema, and pulmonary arterial embolization (for scoring system see ESM Table 4).

\section{Brain}

The brain was removed and fixed in formaldehyde, embedded in paraffin, cut into $1-\mu \mathrm{m}$ sections, and stained with hematoxylin-eosin.

The CA1 and CA2 regions of the hippocampus were studied because they are most vulnerable to ischemic [22, 32] or hypoxic [23] insult. Nuclear pyknosis and eosinophilic degeneration of the cytoplasm were taken as evidence of cell damage. The extent of cell damage was graded as: $1=$ individual cells $(5-10$ per field $)$; $2=$ clusters of cells; $3=$ cell layers; $4=$ marked cell loss. Both right and left hippocampi were examined and the grade of the most severely affected region was used to calculate the brain cell damage score (for detailed description of scoring system see ESM, Fig. 5).

\section{Statistical analysis}

Descriptive statistics are expressed as means and standard deviation or medians and range depending on the distribution of the data. Non-parametric tests were used for comparative statistics because of the small sample sizes and possible non-normal distribution. Changes over time were analyzed with the Friedmann test followed by the
Wilcoxon test for individual comparisons. The MannWhitney $U$ test was used for intergroup comparisons at individual time points. Corrections for multiple comparisons were performed when appropriate. A value of $p$ smaller than 0.05 was considered significant. All calculations were performed with Statistica for Windows (9.0; StatSoft; Europe).

\section{Results}

Hemodynamics

Hemodynamic data are shown in ESM Table 1. The groups did not differ at baseline, but there was a small transient increase in heart rate and mean arterial pressure (MAP) after inflation of the intracranial balloon. The hemodynamic variables remained constant in the control and AICH groups during the study period, except for cardiac output, which was higher in the AICH group at $T_{120}$ and $T_{240}$.

Mean pulmonary arterial pressure and heart rate increased in the two groups with ARDS; stroke volume (SV) decreased but CO remained constant. These changes were greater in the ARDS + AICH group $(p<0.05)$. ITBI remained constant and did not differ between the groups.

\section{Heart rate variability}

Heart rate variability did not change in control animals but decreased in the animals with intracranial hypertension, indicating increased activity of the sympathetic nervous system [33].

\section{Lung}

\section{Gas exchange}

$\mathrm{PaO}_{2}$ and $\mathrm{PaCO}_{2}$ remained constant in the control and AICH groups. $\mathrm{PaCO}_{2}$ increased and $\mathrm{PaO}_{2}$ decreased in the animals with ARDS. $\mathrm{PaO}_{2}$ was lowest in the ARD$\mathrm{S}+\mathrm{AICH}$ group at $240 \mathrm{~min}$ (ESM Table 2).

\section{Density, gas-tissue ratio, and aeration}

Representative CT scans of the lungs of each group at $T_{240}$ are shown in Fig. 1.

Mean total lung density, gas-tissue ratio, and percentages of normal, dystelectatic, and atelectatic tissue are shown in ESM Table 3. Intracranial hypertension alone increased mean lung density and exacerbated the increase in animals with ARDS. Conversely, the 


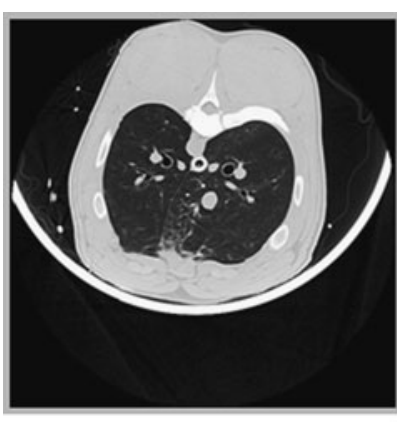

Control

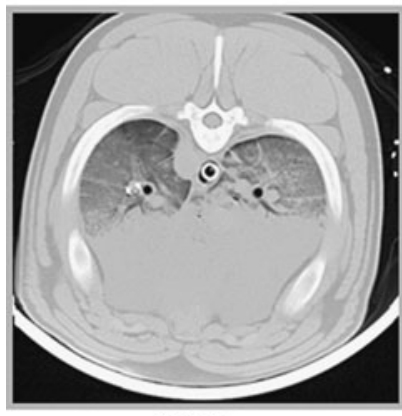

ARDS

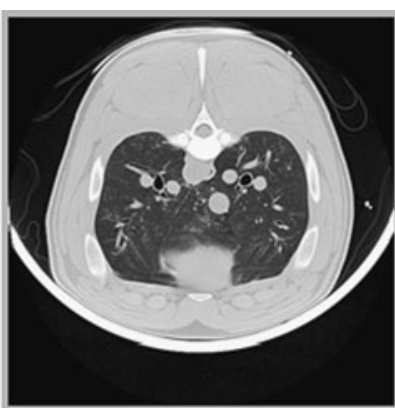

$\mathrm{AICH}$

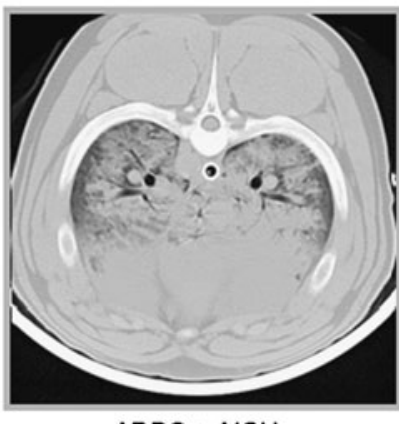

ARDS + AICH
Fig. $1 \mathrm{CT}$ scans of representative animals from each group taken at end-expiration at $240 \mathrm{~min}$. Control control; $A I C H$ acute intracranial hypertension; $A R D S$ acute respiratory distress syndrome; $A R D S+$ $A I C H$ acute respiratory distress syndrome and acute intracranial hypertension

gas-tissue ratio of the lung was reduced by intracranial hypertension in healthy as well as injured lungs with significant increases in poorly aerated and atelectatic lung areas. ARDS induced greater changes which were further exacerbated by AICH (ESM Table 3).

The most pronounced changes occurred in dependent lung regions in all treatment groups (Fig. 2 and ESM Fig. 2).

\section{Extravascular lung water}

The ELWI remained constant in control animals but increased continuously in the AICH group. ELWI was higher in animals with lung injury, and was further increased by intracranial hypertension (Fig. 3; T120; $p<0.05)$.

\section{Lung histology}

The extent of cell damage and the grade of injury were greatest in the ARDS + AICH group. There were more occurrences of edema and vascular embolization in the groups with ARDS. The most extensive edema was seen in the ARDS + AICH group (ESM Table 4).
Brain

Intracranial pressure and tissue oxygen tension

Baseline ICP and tissue oxygen tension $\left(\mathrm{PtiO}_{2}\right)$ were similar in all groups (ESM Table 2). The mean ICP in the $\mathrm{AICH}$ and ARDS + AICH groups was $36.1 \pm 5.8$ and $32.0 \pm 3.5 \mathrm{mmHg}$, respectively. Mean ICP remained unchanged in the control and ARDS groups at $11.5 \pm 0.6$ and $12.1 \pm 0.9 \mathrm{mmHg}$, respectively.

$\mathrm{PtiO}_{2}$ remained constant in control animals, whereas it decreased to below the critical threshold for hypoxic damage of $10-15 \mathrm{mmHg}$ in animals of the treatment groups (ESM Table 2).

\section{Brain density}

Mean brain tissue density was constant in control animals but decreased significantly in all treatment groups, indicating cerebral edema. The control group differed significantly from ARDS + AICH at $240 \mathrm{~min}$ (ESM Fig. 4).

\section{Brain histology}

The mean cerebral damage scores of the hippocampal regions $\mathrm{CA} 1$ and $\mathrm{CA} 2$ were $2.00 \pm 1.00$ in controls, $2.14 \pm 1.21$ in the AICH group, $2.57 \pm 0.98$ in the ARDS group, and $3.43 \pm 0.53$ in animals with both ARDS and AICH. Damage was significantly more severe in the ARDS + AICH group compared with control animals and animals with intracranial hypertension alone $(p<0.05)$. The damage seen in the control animals was most likely due to the intracranial instrumentation (ESM Fig. 3).

\section{NSE and S10OB}

NSE concentrations remained constant whereas S100B decreased significantly in control animals (Fig. 4). Both parameters increased significantly in the animals of the treatment groups with the most marked increase in animals with ARDS. The increase following AICH alone was slighter and peaked later.

\section{Inflammatory mediators}

The IL- $1 \beta$ and IL- 6 concentrations were below the detection threshold in all groups at baseline and only showed a significant increase in the animals with ARDS (ESM Table 5). TNF-alpha concentrations decreased in control and AICH animals and were significantly lower 
Fig. 2 Mean changes in lung density [delta Hounsfield units from $T_{240}$ to $T_{0}($ mean $\left.+\mathrm{SE})\right]$ in control and AICH (upper panel) and in ARDS and ARDS + AICH (lower panel) from segment 1 (nondependent) to segment 10 (dependent). Control control; $A I C H$ acute intracranial hypertension; ARDS acute respiratory distress syndrome; $A R D S+A I C H$ acute respiratory distress syndrome and acute intracranial hypertension. Significant $(p<0.05)$ difference between control and $\mathrm{AICH}$ in segments 1-8 and 10; significant $(p<0.05)$ difference between ARDS and ARDS + AICH in segments 9 and 10
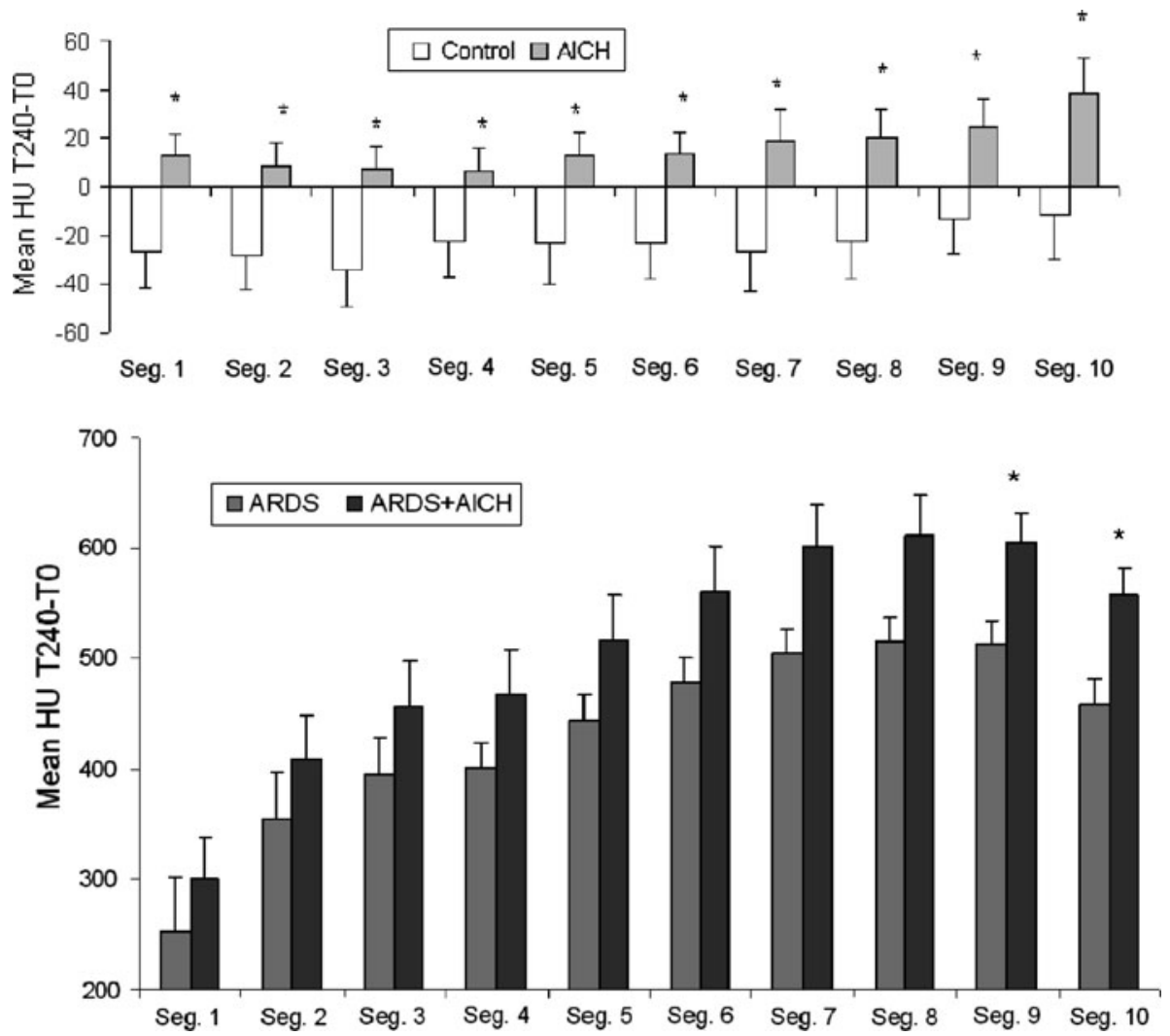

than in animals with ARDS. The highest concentrations were seen in animals with ARDS plus AICH.

\section{Discussion}

The results of this study support the hypothesis that acute intracranial hypertension causes cerebral and pulmonary edema. The latter reduces the gas-tissue ratio in previously healthy lungs without causing histologically detectable pulmonary damage or changes in gas exchange parameters. AICH also exacerbates the pre-existing damage in animals with ARDS.

Plasma concentrations of NSE and S100B increased in all treatment groups. TNF-alpha, IL-6, and IL-1 $\beta$ responded in different ways to intracranial hypertension and acute lung injury, but there was a consistent increase in animals with ARDS which was augmented by intracranial hypertension. Hippocampal damage and cerebral edema was greatest in animals with combined ARDS and intracranial hypertension. This is in agreement with clinical reports [34, 35] and could indicate reciprocal synergistic effects.

The initial pulmonary responses to acute intracranial hypertension are an increase in ELWI and lung density that are not detectable by chest radiography or blood gas

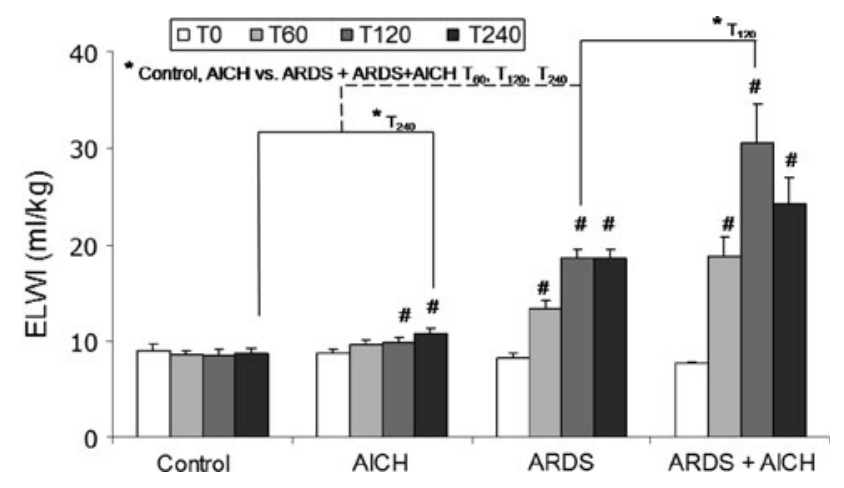

Fig. 3 Extravascular lung water index (ELWI) $($ mean $+\mathrm{SE})$. Control control; AICH acute intracranial hypertension; ARDS acute respiratory distress syndrome; ARDS + AICH acute respiratory distress syndrome and acute intracranial hypertension. "Significant $(p<0.05)$ effect of time in AICH, ARDS, and ARDS + AICH; *significant difference between control versus AICH after 240 min $(p<0.05)$. *Significant difference between ARDS versus ARDS + $\mathrm{AICH}$ at $T_{120}(p<0.05)$

analysis until frank pulmonary edema ensues [36, 37]. Our findings confirm this and underscore the importance of ELWI as an early indicator of lung injury and ARDS [38].

Proposed mechanisms for the development of neurogenic pulmonary edema, i.e., the increase in ELWI after an acute neurologic injury [5] are a massive increase in cerebral sympathetic outflow causing acute pulmonary 

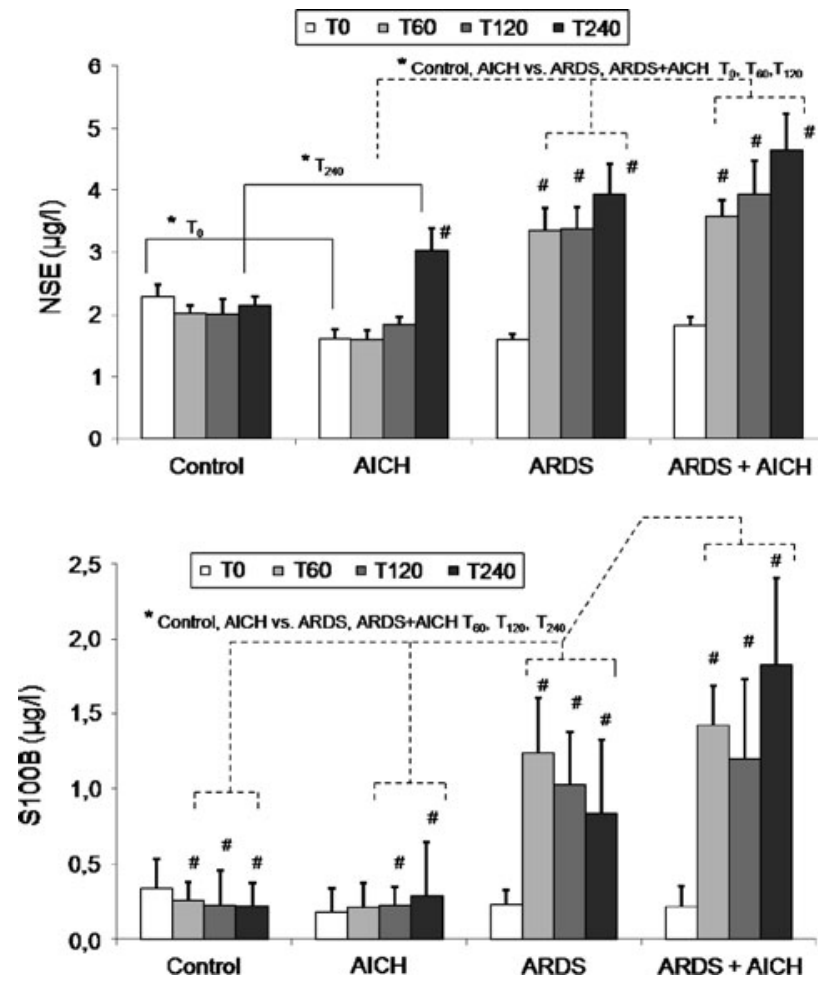

Fig. 4 Plasma concentration of neuron-specific enolase (NSE) and S100B (mean + SE) in control, AICH, ARDS, ARDS + AICH from $T_{0}$ to $T_{240}$. Control control; AICH acute intracranial hypertension; $A R D S$ acute respiratory distress syndrome; $A R D S+A I C H$ acute respiratory distress syndrome and acute intracranial hypertension. NSE: " significant $(p<0.05)$ effect of time in $\mathrm{AICH}$ ARDS and ARDS + AICH; *significant $(p<0.05)$ difference between control and AICH at $T_{0}$ and $T_{240}$. Significant $(p<0.05)$ difference between control, AICH and ARDS, ARDS + AICH at $\mathrm{T}_{60}, \mathrm{~T}_{120}$, and $\mathrm{T}_{240}$. S100B: " significant $(p<0.05)$ effect of time in all groups; significant $(p<0.05)$ difference between control and AICH at $T_{240}$. Significant difference between control, AICH and ARDS, ARDS + AICH at $T_{60}, T_{120}$, and $T_{240}$

venoconstriction with a fluid shift into the interstitium [39]. There is a simultaneous activation of inflammatory responses that further increase the permeability of the endothelium for proteins [5, 40, 41].

The reduction in heart rate variability supports the role of sympathetic activation, but we did not see the blood pressure increase that was observed in a similar animal model, in which inflation of an intracranial Fogarty catheter was used to induce brain death [5, 42]. Pulmonary venoconstriction is also unlikely to increase arterial pressures, and the increase in pulmonary arterial pressures in the animals with ARDS is probably a consequence and not a cause of pulmonary pathology. Su et al. [33] concluded that the increase in sympathetic activity may be relative to decreased parasympathetic activity secondary to brain stem damage. Avlonitis et al. [4] showed that the inflammatory response is significantly decreased in brain-dead animals when the initial catecholamine storm is treated with phentolamine and the following hypotension is treated with noradrenaline. Our results suggest that not only brain death but also isolated $\mathrm{AICH}$ might induce NSE release and systemic inflammation. A recent study showed that beta-adrenergic receptor blockade reduced mortality in elderly patients with blunt head injuries [43].

The importance of organ cross talk and the clinical impact of such organ interaction is reflected in the results of a study by Hopkins et al. [44], who found that more than $20 \%$ of ARDS survivors had a reduced quality of life with a significantly elevated rate of depression and anxiety.

The hippocampus is exquisitely sensitive to damage and Hofmann et al. [45] detected hippocampal atrophy in patients after only minor head trauma. We were unable to determine if AICH or ARDS alone causes hippocampal damage, probably as a result of the intracranial instrumentation of the control animals and short study duration, but this is likely because AICH and ARDS together caused significant damage and cerebral CT scans revealed cerebral edema in the ARDS animals. The problem might also be the small sample size that only had a power of $50 \%$ to detect such small increases even in a one-sided test. Hypoxia is the most likely factor in our animals, as evidence of decreased perfusion was found in the CT scans, and the $\mathrm{PtiO}_{2}$ values in the $\mathrm{AICH}$ and $\mathrm{AICH}+\mathrm{ARDS}$ groups were lower than the critical threshold for cell damage of $15 \mathrm{mmHg}$ described by Valadka et al. [46].

This raises the clinical question of whether the recommended arterial oxygen saturation of greater than $90 \%$ [47] is adequate in ARDS patients with concomitant brain injury. It would be interesting to see whether the behavior of surviving animals correlated with the laboratory and CT evidence of cerebral hypoxia, edema, and inflammation [48].

The time courses of plasma concentrations of NSE and S100 are not consistent with intracranial hypertension being the secretory stimulus, and the brain is not necessarily the source [49]. Although there is a slight increase in the AICH group after $240 \mathrm{~min}$, the largest and most rapid increases were seen in the animals with ARDS. It is not possible from our data to differentiate between pulmonary injury or a direct effect of oleic acid as the responsible factor for NSE and S100 release, but it is likely that the increase of the NSE might partially be caused by hemolysis [50, 51]. NSE directly correlates with the amount of hemolysis and the hemoglobin level, because it is found in red blood cells (RBC). The hypoxia marker S100, on the other hand, is not affected by hemolysis [52].

Plasma concentrations of the inflammatory markers TNF-alpha, IL-6, and IL- $1 \beta$ responded differently to AICH and ARDS, with a consistent increase in the ARDS groups that was further augmented by AICH. A cytokinemediated inflammatory response might be causally associated with lung damage after AICH. Polymorphonuclear leukocytes (PMNs), the earliest immune cells to be 
recruited at the injury site [53], may contribute to pulmonary dysfunction and altered vascular permeability through release and production of cytokines and reactive oxygen species [54-56].

TNF-alpha increases after $\mathrm{AICH}$, but it cannot be said if this causes or is a consequence of the observed pulmonary changes. The absence of an interleukin response in the AICH group might be due to the suppressant effects of midazolam and ketamine on cytokine secretion $[57,58]$ that masked a small increase. A study published by Bickenbach et al. only detected an IL-6 increase after $4 \mathrm{~h}$, so our sampling period might have been too short [59].

Our results strongly suggest the existence of organ cross talk, but the exact pathophysiological interactions are unknown. Further studies on immunohistology and transcription patterns of mediators in the brain would be useful.

The study has some limitations that could interfere with interpretation of the data. First of all, there was no group without intracranial instrumentation as a control for hippocampal damage in ARDS animals. Measuring NSE and S100 in cerebrospinal fluid (SCF) would have helped determine their source, but spinal tap is difficult in pigs, and bleeding could give false results because cerebral markers are found in significant concentrations in blood cells. The inflammatory response to the procedure could alter cytokine concentrations, and the associated CSF loss could alter the ICP. Inducing ARDS before intracranial hypertension is not the usual clinical sequence of events. Technical constraints limited the study duration to $240 \mathrm{~min}$ so that delayed interactions between the lung and brain may have been missed.
The lung protective ventilation strategy employed in this study minimizes pulmonary damage, reduces cytokine release [60], and improves cerebral blood flow [61], and thereby may have lessened the interactions between pulmonary and cerebral damage and thus made their detection difficult [62-64]. Even though ICP was held constant, the hypercapnia in the ARDS and AICH + ARDS groups might have altered cerebral perfusion and respiratory drive, causing hippocampal lesions. The balloon model used to increase intracranial pressure does not reproduce every aspect of the ICH commonly seen in traumatic brain injury [1], but it has the advantage of providing a stable level of ICP.

\section{Conclusions}

Acute intracranial hypertension not only damages healthy lungs, but also exacerbates the damage in lungs with preexisting lesions. And, vice versa, acute lung injury can precipitate cerebral damage during intracranial hypertension. Extravascular lung water should be monitored in patients with acute brain injury.

Conflict of interest The authors declare that they have no competing interests.

Open Access This article is distributed under the terms of the Creative Commons Attribution Noncommercial License which permits any noncommercial use, distribution, and reproduction in any medium, provided the original author(s) and source are credited.

\section{References}

1. Stocchetti N, Zanaboni C, Colombo A, Citerio G, Beretta L, Ghisoni L, Zanier ER, Canavesi K (2008) Refractory intracranial hypertension and "secondtier" therapies in traumatic brain injury. Intensive Care Med 34:461-467

2. Bratton SL, Davis RL (1997) Acute lung injury in isolated traumatic brain injury. Neurosurgery 40:707-712; discussion 712

3. Zygun DA, Kortbeek JB, Fick GH, Laupland KB, Doig CJ (2005) Nonneurologic organ dysfunction in severe traumatic brain injury. Crit Care Med 33:654-660

4. Touho H, Karasawa J, Shishido H, Yamada K, Yamazaki Y (1989) Neurogenic pulmonary edema in the acute stage of hemorrhagic cerebrovascular disease. Neurosurgery 25:762-768
5. Avlonitis VS, Wigfield CH, Kirby JA, Dark JH (2005) The hemodynamic mechanisms of lung injury and systemic inflammatory response following brain death in the transplant donor. Am J Transplant 5:684-693

6. Kalsotra A, Zhao J, Anakk S, Dash PK, Strobel HW (2007) Brain trauma leads to enhanced lung inflammation and injury: evidence for role of P4504Fs in resolution. J Cereb Blood Flow Metab 27:963-974

7. Mascia L (2009) Acute lung injury in patients with severe brain injury: a double hit model. Neurocrit Care 11:417-426

8. Lopez-Aguilar J, Quilez ME, MartiSistac O, Garcia-Martin C, Fuster G, Puig F, Flores C, Villar J, Artigas A, Blanch L (2010) Early physiological and biological features in three animal models of induced acute lung injury. Intensive Care Med 36:347-355
9. Gonzalvo R, Marti-Sistac O, Blanch L, Lopez-Aguilar J (2007) Bench-tobedside review: brain-lung interaction in the critically ill-a pending issue revisited. Crit Care 11:216

10. Lou J, Donati YR, Juillard P, Giroud C, Vesin C, Mili N, Grau GE (1997) Platelets play an important role in TNFinduced microvascular endothelial cell pathology. Am J Pathol 151:1397-1405

11. Vilalta A, Sahuquillo J, Rosell A, Poca MA, Riveiro M, Montaner J (2008) Moderate and severe traumatic brain injury induce early overexpression of systemic and brain gelatinases. Intensive Care Med 34:1384-1392

12. Lopez-Aguilar J, Villagra A, Bernabe F, Murias G, Piacentini E, Real J, Fernandez-Segoviano P, Romero PV, Hotchkiss JR, Blanch L (2005) Massive brain injury enhances lung damage in an isolated lung model of ventilatorinduced lung injury. Crit Care Med 33:1077-1083 
13. Nguyen DN, Spapen H, Su F, Schiettecatte J, Shi L, Hachimi-Idrissi S, Huyghens L (2006) Elevated serum levels of S-100beta protein and neuronspecific enolase are associated with brain injury in patients with severe sepsis and septic shock. Crit Care Med 34:1967-1974

14. Woertgen C, Rothoerl RD, Holzschuh M, Metz C, Brawanski A (1997) Comparison of serial S-100 and NSE serum measurements after severe head injury. Acta Neurochir (Wien) 139:1161-1164; discussion 1165

15. Fries M, Bickenbach J, Henzler D, Beckers S, Dembinski R, Sellhaus B, Rossaint R, Kuhlen R (2005) S-100 protein and neurohistopathologic changes in a porcine model of acute lung injury. Anesthesiology 102:761-767

16. Ingebrigtsen T, Romner B (1996) Serial S-100 protein serum measurements related to early magnetic resonance imaging after minor head injury. Case report. J Neurosurg 85:945-948

17. Hardemark HG, Almqvist O, Johansson T, Pahlman S, Persson L (1989) S-100 protein in cerebrospinal fluid after aneurysmal subarachnoid haemorrhage: relation to functional outcome, late CT and SPECT changes, and signs of higher cortical dysfunction. Acta Neurochir (Wien) 99:135-144

18. Hardemark HG, Ericsson N, Kotwica Z, Rundstrom G, Mendel-Hartvig I, Olsson Y, Pahlman S, Persson L (1989) S-100 protein and neuron-specific enolase in CSF after experimental traumatic or focal ischemic brain damage. J Neurosurg 71:727-731

19. Horn M, Seger F, Schlote W (1995) Neuron-specific enolase in gerbil brain and serum after transient cerebral ischemia. Stroke 26:290-296; discussion 296-297

20. Unden J, Astrand R, Waterloo K, Ingebrigtsen $\mathrm{T}$, Bellner J, Reinstrup $\mathrm{P}$, Andsberg G, Romner B (2007) Clinical significance of serum S100B levels in neurointensive care. Neurocrit Care 6:94-99

21. Herrmann M, Jost S, Kutz S, Ebert AD, Kratz T, Wunderlich MT, Synowitz H (2000) Temporal profile of release of neurobiochemical markers of brain damage after traumatic brain injury is associated with intracranial pathology as demonstrated in cranial computerized tomography.

J Neurotrauma 17:113-122

22. Kirino T, Sano K (1984) Selective vulnerability in the gerbil hippocampus following transient ischemia. Acta Neuropathol 62:201-208
23. Ng T, Graham DI, Adams JH, Ford I (1989) Changes in the hippocampus and the cerebellum resulting from hypoxic insults: frequency and distribution. Acta Neuropathol 78:438-443

24. Rohde V, Rohde I, Thiex R, Ince A, Jung A, Duckers G, Groschel K, Rottger C, Kuker W, Muller HD, Gilsbach JM (2002) Fibrinolysis therapy achieved with tissue plasminogen activator and aspiration of the liquefied clot after experimental intracerebral hemorrhage: rapid reduction in hematoma volume but intensification of delayed edema formation. J Neurosurg 97:954-962

25. Broccard AF, Shapiro RS, Schmitz LL, Ravenscraft SA, Marini JJ (1997) Influence of prone position on the extent and distribution of lung injury in a high tidal volume oleic acid model of acute respiratory distress syndrome. Crit Care Med 25:16-27

26. Pelosi P, D'Andrea L, Vitale G, Pesenti A, Gattinoni L (1994) Vertical gradient of regional lung inflation in adult respiratory distress syndrome. Am J Respir Crit Care Med 149:8-13

27. Appelberg J, Janson C, Lindberg E, Pavlenko T, Hedenstierna G (2010) Lung aeration during sleep in patients with obstructive sleep apnoea. Clin Physiol Funct Imaging 30:301-307

28. Rylander C, Tylen U, Rossi-Norrlund R, Herrmann P, Quintel M, Bake B (2005) Uneven distribution of ventilation in acute respiratory distress syndrome. Crit Care 9:R165-R171

29. Rozsa L, Grote EH, Egan P (1989) Traumatic brain swelling studied by computerized tomography and densitometry. Neurosurg Rev 12:133-140

30. Takahashi N, Satou C, Higuchi T, Shiotani M, Maeda H, Hirose Y (2010) Quantitative analysis of brain edema and swelling on early postmortem computed tomography: comparison with antemortem computed tomography. Jpn J Radiol 28:349-354

31. Bigger JT Jr, Fleiss JL, Steinman RC, Rolnitzky LM, Kleiger RE, Rottman JN (1992) Frequency domain measures of heart period variability and mortality after myocardial infarction. Circulation 85:164-171

32. Schmidt-Kastner R, Freund TF (1991) Selective vulnerability of the hippocampus in brain ischemia. Neuroscience 40:599-636

33. Su CF, Kuo TB, Kuo JS, Lai HY, Chen HI (2005) Sympathetic and parasympathetic activities evaluated by heart-rate variability in head injury of various severities. Clin Neurophysiol 116:1273-1279
34. Holland MC, Mackersie RC, Morabito D, Campbell AR, Kivett VA, Patel R, Erickson VR, Pittet JF (2003) The development of acute lung injury is associated with worse neurologic outcome in patients with severe traumatic brain injury. J Trauma 55:106-111

35. Mascia L, Sakr Y, Pasero D, Payen D, Reinhart K, Vincent JL (2008) Extracranial complications in patients with acute brain injury: a post hoc analysis of the SOAP study. Intensive Care Med 34:720-727

36. Halperin BD, Feeley TW, Mihm FG, Chiles C, Guthaner DF, Blank NE (1985) Evaluation of the portable chest roentgenogram for quantitating extravascular lung water in critically ill adults. Chest 88:649-652

37. Sakka SG, Klein M, Reinhart K, MeierHellmann A (2002) Prognostic value of extravascular lung water in critically ill patients. Chest 122:2080-2086

38. Gattinoni L, Caironi P, Cressoni M, Chiumello D, Ranieri VM, Quintel M, Russo S, Patroniti N, Cornejo R, Bugedo G (2006) Lung recruitment in patients with the acute respiratory distress syndrome. N Engl J Med 354:1775-1786

39. Dauber IM, Weil JV (1983) Lung injury edema in dogs. Influence of sympathetic ablation. J Clin Invest 72:1977-1986

40. Kowalski ML, Didier A, Kaliner MA (1989) Neurogenic inflammation in the airways. I. Neurogenic stimulation induces plasma protein extravasation into the rat airway lumen. Am Rev Respir Dis 140:101-109

41. Rassler B, Reissig C, Briest W, Tannapfel A, Zimmer HG (2003) Catecholamine-induced pulmonary edema and pleural effusion in ratsalpha- and beta-adrenergic effects. Respir Physiol Neurobiol 135:25-37

42. Takada M, Nadeau KC, Hancock WW, Mackenzie HS, Shaw GD, Waaga AM, Chandraker A, Sayegh MH, Tilney NL (1998) Effects of explosive brain death on cytokine activation of peripheral organs in the rat. Transplantation 65:1533-1542

43. Inaba K, Teixeira PG, David JS, Chan LS, Salim A, Brown C, Browder T, Beale E, Rhee P, Demetriades D (2008) Beta-blockers in isolated blunt head injury. J Am Coll Surg 206:432-438

44. Hopkins RO, Weaver LK, Collingridge D, Parkinson RB, Chan KJ, Orme JF Jr (2005) Two-year cognitive, emotional, and quality-of-life outcomes in acute respiratory distress syndrome. Am J Respir Crit Care Med 171:340-347 
45. Hofman PA, Stapert SZ, van Kroonenburgh MJ, Jolles J, de Kruijk J, Wilmink JT (2001) MR imaging, single-photon emission CT, and neurocognitive performance after mild traumatic brain injury. AJNR Am J Neuroradiol 22:441-449

46. Valadka AB, Gopinath SP, Contant CF, Uzura M, Robertson CS (1998) Relationship of brain tissue PO2 to outcome after severe head injury. Crit Care Med 26:1576-1581

47. Hopkins RO, Weaver LK, Pope D, Orme JF, Bigler ED, Larson LV (1999) Neuropsychological sequelae and impaired health status in survivors of severe acute respiratory distress syndrome. Am J Respir Crit Care Med 160:50-56

48. Hopkins RO, Gale SD, Weaver LK (2006) Brain atrophy and cognitive impairment in survivors of acute respiratory distress syndrome. Brain Inj 20:263-271

49. Routsi C, Stamataki E, Nanas S, Psachoulia C, Stathopoulos A, Koroneos A, Zervou M, Jullien G, Roussos C (2006) Increased levels of serum S100B protein in critically ill patients without brain injury. Shock 26:20-24

50. Florio P, Marinoni E, Di Iorio R, Bashir M, Ciotti S, Sacchi R, Bruschettini M, Lituania M, Serra G, Michetti F, Petraglia F, Gazzolo D (2006) Urinary S100B protein concentrations are increased in intrauterine growthretarded newborns. Pediatrics 118:e747-e754
51. Gazzolo D, Florio P, Ciotti S, Marinoni E, di Iorio R, Bruschettini M, Sacchi R, Serra G, Lituania M, Michetti F (2005) $\mathrm{S} 100 \mathrm{~B}$ protein in urine of preterm newborns with ominous outcome. Pediatr Res 58:1170-1174

52. Beaudeux JL, Leger P, Dequen L, Gandjbakhch I, Coriat P, Foglietti MJ (2000) Influence of hemolysis on the measurement of S-100beta protein and neuron-specific enolase plasma concentrations during coronary artery bypass grafting. Clin Chem 46:989-990

53. Witko-Sarsat V, Rieu P, DescampsLatscha B, Lesavre P, HalbwachsMecarelli L (2000) Neutrophils: molecules, functions and pathophysiological aspects. Lab Invest 80:617-653

54. Goldman G, Welbourn R, Kobzik L, Valeri CR, Shepro D, Hechtman HB (1992) Reactive oxygen species and elastase mediate lung permeability after acid aspiration. J Appl Physiol 73:571-575

55. Sibille Y, Marchandise FX (1993) Pulmonary immune cells in health and disease: polymorphonuclear neutrophils. Eur Respir J 6:1529-1543

56. Strieter RM, Kunkel SL (1994) Acute lung injury: the role of cytokines in the elicitation of neutrophils. J Investig Med 42:640-651

57. Beilin B, Rusabrov Y, Shapira Y, Roytblat L, Greemberg L, Yardeni IZ, Bessler H (2007) Low-dose ketamine affects immune responses in humans during the early postoperative period. Br J Anaesth 99:522-527

58. Haitsma JJ, Lachmann B, Papadakos PJ (2009) Additives in intravenous anesthesia modulate pulmonary inflammation in a model of LPSinduced respiratory distress. Acta Anaesthesiol Scand 53:176-182
59. Bickenbach J, Zoremba N, Fries M, Dembinski R, Doering R, Ogawa E, Rossaint R, Kuhlen R (2009) Low tidal volume ventilation in a porcine model of acute lung injury improves cerebral tissue oxygenation. Anesth Analg 109:847-855

60. Pinheiro de Oliveira R, Hetzel MP, dos Anjos Silva M, Dallegrave D, Friedman G (2010) Mechanical ventilation with high tidal volume induces inflammation in patients without lung disease. Crit Care 14:R39

61. Lowe GJ, Ferguson ND (2006) Lungprotective ventilation in neurosurgical patients. Curr Opin Crit Care 12:3-7

62. Mascia L, Zavala E, Bosma K, Pasero D, Decaroli D, Andrews P, Isnardi D, Davi A, Arguis MJ, Berardino M, Ducati A (2007) High tidal volume is associated with the development of acute lung injury after severe brain injury: an international observational study. Crit Care Med 35:1815-1820

63. Valenza F, Guglielmi M, Maffioletti M, Tedesco C, Maccagni P, Fossali T, Aletti G, Porro GA, Irace M, Carlesso E, Carboni N, Lazzerini M, Gattinoni L (2005) Prone position delays the progression of ventilator-induced lung injury in rats: does lung strain distribution play a role? Crit Care Med 33:361-367

64. Vlahakis NE, Schroeder MA, Limper AH, Hubmayr RD (1999) Stretch induces cytokine release by alveolar epithelial cells in vitro. Am J Physiol 277:L167-L173 